\begin{abstract}
In Singapore, 10.5 percent of adults aged between 18 and 69 years are affected by asthma. Suboptimal asthma control imposes a significant burden on healthcare systems and society. Short-acting betaagonists (SABA) monotherapy had been the standard asthma treatment for many years in patients with mild asthma symptoms. However, according to current guidelines and new recommendations, SABAs are no longer recommended as the preferred reliever for patients when they are symptomatic and should not be used as monotherapy due to significant safety concerns and poor outcomes. In this article, we will review the current guideline recommendations and accompanying evidence for the treatment and management of asthma in clinical practice.
\end{abstract}

Keywords: asthma, inhaled corticosteroid, shortacting beta- 2 agonist, asthma control

SFP202 I; 47(7) : 6-8

\section{THE BURDEN OF ASTHMA IN SINGAPORE}

Asthma is a chronic inflammatory disorder of the airways characterised by inflammation and constriction of the air passages. ${ }^{1}$ Globally, asthma affects 334 million patients of all age groups and is one of the most common chronic respiratory diseases seen in Singapore's primary care. ${ }^{2,3}$

10.5 percent of Singaporean adults aged between 18 and 69 years are affected by asthma. ${ }^{3}$ Patients with asthma often require long-term medical treatment of their condition and may occasionally seek emergency rescue therapy at acute healthcare facilities or be hospitalised during exacerbations. ${ }^{3}$ Poor asthma control and high exacerbation rates result in a high percentage of patients missing work or school. The Asthma Insight and Management (AIM) survey reported 48 percent of patients aged 12 years and older in Singapore having missed work or school on an average of 7.7 days due to asthma in the past year. ${ }^{4}$

\section{CHAN KWOK WAI ADRIAN}

Respiratory Physician

Mouth Elizabeth Novena Hospital Singapore
Poorly controlled asthma imposes a significant economic burden. A recent cross-sectional online survey was administered to Singapore residents to quantify the economic burden of asthma in Singapore by the level of symptom control. The total annual cost of adult and childhood asthma in Singapore was estimated to be SGD 1.74 billion (US $\$ 1.25$ billion) and SGD 0.35 billion (US $\$ 0.25$ billion), respectively. Combined, the annual economic burden of asthma in Singapore is SGD 2.09 billion (US $\$ 1.50$ billion) with 79 percent resulting from lost productivity. ${ }^{5}$ Therefore, better control of asthma is crucial to bring about not only health improvements but also healthcare expenditure savings and productivity gains.

\section{UNMET NEEDS IN ASTHMA}

According to guidelines, poorly controlled outcomes and exacerbations of asthma can be reduced with preventer (or controller) medications, particularly inhaled corticosteroid (ICS) - the mainstay of long-term asthma management. ${ }^{6-9}$ Singapore was the lowest among eight countries in the AsiaPacific region with only one in four patients (26 percent) with asthma aged 12 years and older reporting controller medication use in the past month. ${ }^{4}$

A national audit conducted in Singapore identified one in three patients with a severe asthma exacerbation requiring mechanical ventilation or intensive care unit (ICU) admission was not on ICS before the exacerbation. ${ }^{10}$ The audit further reported the underuse of ICS and spirometry, inconsistent follow-up, and high smoking rates as gaps in care among severe asthma cases in Singapore. ${ }^{10}$ In the Asia-Pacific region, despite the proven efficacy of ICS medications, the majority of patients continue to rely on reliever medications to treat acute symptoms, resulting in suboptimal control. ${ }^{5,11}$ To reduce the impact of asthma in Singapore, more optimal ICS use as part of long-term management is needed. ${ }^{5,6}$

\section{RETHINKING ASTHMA TREATMENT: THE PROBLEM WITH SABA-ONLY TREATMENT}

Short-acting beta-agonists (SABA) have been the mainstay treatment in patients with asthma. However, expert opinions, emerging evidence, and guidelines on the optimal use of beta-agonists have resulted in an evolution in our understanding of the impacts of this reliance of SABA use on patient outcomes. ${ }^{12}$

Higher use of SABA is associated with adverse clinical outcomes. Dispensing of three or more SABA inhalers (canisters) per year is associated with a higher risk of severe exacerbations and the use of one canister per month is associated with increased mortality. ${ }^{6,13}$ Regular use of SABA, 
even for one-two weeks, is associated with adverse effects. ${ }^{6}$ Conflicting perceptions and poor communication between patients and physicians about asthma status have been cited as a contributing factor to the over-reliance on SABA and the underuse of ICS. ${ }^{14}$ Over-reliance on SABA puts patients at an increased risk of asthma attacks, urgent hospitalisation, and even asthma-related death. . $^{6,12,13}$

Patients with frequent exacerbations in asthma due to SABA monotherapy are routinely managed using oral corticosteroids (OCS), which then raises concerns associated with a high cumulative OCS dose and the adverse effects of these agents. ${ }^{15}$ Adverse effects of long-term OCS include obesity, diabetes, osteoporosis, cataracts, cardiovascular events, and hypertension. ${ }^{6,12}$ Treatment approaches to minimise the need for OCS are, therefore, a high priority.

Based on significant evidence on safety issues (severe exacerbations and death) with SABA-only treatment ${ }^{12-14}$ for asthmaand the supporting data that adding ICSs significantly reduces the risk of asthma deaths, hospitalisation, and exacerbations requiring OCS, ${ }^{16-18}$ the Global Initiative for Asthma (GINA) now no longer recommends treatment of asthma in adults and adolescents with SABA alone. ${ }^{6}$

\section{OPTIMAL ICS USE AS PART OF LONG-TERM MANAGEMENT: TREATMENT GUIDELINES}

The Global Initiative for Asthma (GINA) recommends that all patients with asthma aged 12 years and above receive ICS-containing controller treatment to reduce their risk of serious exacerbations and to control symptoms. For reliever recommendation, the current GINA report consists of two "tracks" or reliever options. ${ }^{6}$

The first track utilises low-dose ICS- formoterol as the reliever. Track two, using SABA as the reliever, is suggested only as an alternative approach if track one is not possible or not preferred by a patient with no exacerbations on their current therapy. Track one is the preferred GINA approach based on the evidence of a reduction in risk of severe exacerbations compared with using SABA reliever, with similar symptom control and similar lung function.

Evidence for these recommendations was prompted by large randomised controlled trials and real-world studies. ${ }^{19-22}$ The Symbicort Given as-needed in Mild Asthma (SYGMA) trial programme consisting of SYGMA 1 and 2 Phase III trials in more than 8000 patients showed the efficacy and safety of budesonide-formoterol as a reliever therapy in the absence of regular maintenance treatment in patients with mild asthma. ${ }^{19,20}$ The SYGMA 1 trial $^{19}$ showed the superiority of budesonide-formoterol over as-needed SABA as a reliever agent, both for symptom control and the prevention of exacerbations, with no evidence of budesonide-formoterol overuse. The SYGMA 2 trial $^{20}$ confirmed noninferiority in exacerbation reduction of the as-needed budesonideformoterol combination compared to the maintenance ICS plus as-needed SABA regimen.
Starting with SABA alone trains the patient to regard it as their primary asthma treatment. ${ }^{6,14}$ Physicians would, therefore, need to review SABA use with patients, particularly to identify those using three or more SABA inhalers per year and educate them on the new GINA strategy of using ICScontaining controller treatment for relief of symptoms in place of SABA therapy. ${ }^{6,12}$

The Singapore ACE Clinical Guidance (ACG) $)^{2,3}$ had also outlined recommendations on ICS as the mainstay treatment. ICS-formoterol has been approved in Singapore for the treatment of asthma to achieve overall asthma control, including the prevention and relief of symptoms as well as the reduction of the risk of exacerbations. ${ }^{2,3}$

ACE Clinical Guidance (ACG) guidelines recommend maintaining ICS as the mainstay of long-term asthma management as it addresses airway inflammation, reduces poor asthma outcomes, ${ }^{6,16-18,23}$ and represents the most effective preventer option across the asthma treatment steps. ${ }^{2,3}$ In line with the recent update with GINA, ACG does not recommend the use of SABA alone (without a preventer) for the long-term treatment of patients aged six years and older, even in those with infrequent or minor symptoms. As demonstrated in the SYGMA trials ${ }^{20,21}$, patients relying on SABA alone (without a preventer) are more likely to experience poor asthma outcomes, such as the need for OCS or hospitalisations compared to patients using an ICS containing treatment as the preventer and with SABA as the reliever. Nonetheless, SABA is still recommended for shortterm relief of symptoms, but only with ICS use.

Across the asthma treatment steps highlighted in the guideline, daily ICS-containing treatment is the most effective preventer option and is important for patients at a higher risk of poor asthma outcomes. The decision regarding the choice or adjustment of preventer treatment should be guided by asthma symptoms, risk of poor asthma outcomes, and influencing factors described in the guideline. ${ }^{2,3}$ If asthma symptoms remain consistently managed for more than three-six months, clinicians can consider stepping down the preventer treatment gradually, to the lowest effective ICS dose. However, ACG does not recommend stopping ICS altogether in patients with asthma aged five years or older as this is associated with an increased risk of exacerbations.

\section{CONCLUSION}

Optimised control of asthma is crucial as it has the potential to generate not only health improvements but also improve productivity and reduce the economic burden of the country. While the negative effect of SABA monotherapy and overuse is clearly understood, physicians should continue to review SABA use in their patients and educate patients with asthma on new guidelines on the recommended treatment strategy - ICS-containing controller treatment in place of SABA therapy to reduce patient's risk of serious exacerbations and improve asthma control. 


\section{REFERENCES}

I. Braman SS. The global burden of asthma. Chest. 2006 Jul; I30(I Suppl):4S-I2S. doi: I0.1378/chest. I30.I_suppl.4S.PMID: I6840363.

2. Health Information Division, Ministry of Health, Singapore. Primary Care Survey [Internet]. SG: MOH, SG; [updated 2014; cited 202I June 28]. Available from: www.moh.gov.sg/resourcesstatistics/reports/primary-care-survey-2014-report.

3. Tan NC, Nguyen HV, Lye WK, Sankari U, Nadkarni NV.Trends and predictors of asthma costs:results from a I0-year longitudinal study. Eur Respir J. 2016 Mar;47(3):80 I-9. doi: I0.I I83/I3993003.00 I882015. Epub 2015 Dec 2. PMID: 26647437.

4. Thompson PJ, Salvi S, Lin J, Cho YJ, Eng P, Abdul Manap R, Boonsawat W, Hsu JY, Faruqi RA, Moreno-Cantu JJ, Fish JE, Ho JC. Insights, attitudes and perceptions about asthma and its treatment: findings from a multinational survey of patients from 8 Asia-Pacific countries and Hong Kong. Respirology. 2013 Aug;18(6):957-67. doi: I0.1 I I I/resp. I2I37. PMID: 23730953.

5. Finkelstein EA, Lau E, Doble B, Ong B, Koh MS. Economic burden of asthma in Singapore. BMJ Open Respir Res. 2021 Mar;8(I):e000654. doi: I0.II36/bmjresp-2020-000654. PMID: 33737309; PMCID: PMC7978329.

6. Global Initiative for Asthma (GINA). 202I GINA Report, Global strategy for asthma management and prevention [Internet]. US: GINA; [updated 202I; cited 202I June 28].Available from: https:// ginasthma.org/gina-reports/

7. National Institute for Health and Care Excellence (NICE).Asthma: diagnosis, monitoring and chronic asthma management [Internet] US: NICE; [updated 202I March 22; cited 202I June 28]. Available from: https://www.nice.org.uk/guidance/ng80

8. British Thoracic Society/Scottish Intercollegiate Guidelines Network (BTS/SIGN). British guideline on the management of asthma - a national clinical guideline [Internet]. UK: BTS/SIGN; [updated 2019 July; cited 202I June 27]. Available from: https:// www.brit-thoracic.org.uk/quality-improvement/guidelines/ asthmal

9. National Asthma Council Australia. The Australian Asthma Handbook, version 2.I [Internet]. Australia: National Asthma Council Australia; [updated 2020 September; cited 202I June 27]. Available from: https://www.asthmahandbook.org.au/about

10. Yii A, Puah SH, Lim HF, Tay TR, Neo LP, Li A, Lau P, Tan RA, Tan LL, Abisheganaden J, Lim TK.A national audit of severe life-threatening asthma in Singapore. Eur Respir J. 2018;52: Suppl. 62, PA3957.

II. Lai CK, Kim YY, Kuo SH, Spencer M,Williams AE. on behalf of the Asthma Insights and Reality in Asia Pacific Steering Committee. Cost of asthma in the Asia-Pacific region. Eur Respir Rev. 2006;15(98):10-6.

12. Kaplan A, Mitchell PD, Cave AJ, Gagnon R, Foran V, Ellis AK. Effective Asthma Management: Is It Time to Let the AIR out of SABA? J Clin Med. 2020 Mar 27;9(4):921. doi: I0.3390/jcm904092।. PMID 32230875; PMCID: PMC7230470.

13. Nwaru BI, Ekström M, Hasvold P, Wiklund F, Telg G, Janson C. Overuse of short-acting $\beta_{2}$-agonists in asthma is associated with increased risk of exacerbation and mortality: a nationwide cohort study of the global SABINA programme. Eur Respir J. $2020 \mathrm{Apr}$ 16;55(4):1901872. doi: 10.1 I83/I3993003.01872-2019. PMID: 31949। II; PMCID: PMC7|60635
14. O'Byrne PM, Jenkins C, Bateman ED. The paradoxes of asthma management: time for a new approach? Eur Respir J. 2017 Sep 9;50(3):170|103. doi: 10.1/83/13993003.01/03-2017. PMID 28889114.

15. Chung LP, Upham JW, Bardin PG, Hew M. Rational oral corticosteroid use in adult severe asthma: $\mathrm{A}$ narrative review. Respirology. 2020 Feb;25(2):I6I-172. doi: 10.1III/resp.13730. Epub 2019 Nov 12. PMID: 31713955 ; PMCID: PMC7027745.

16. Suissa S, Ernst P, Benayoun S, Baltzan M, Cai B. Low-dose inhaled corticosteroids and the prevention of death from asthma. N Engl J Med. 2000 Aug 3;343(5):332-6. doi: 10.1056/ NEJM200008033430504. PMID: I0922423.

17. Suissa S, Ernst P, Kezouh A. Regular use of inhaled corticosteroids and the long term prevention of hospitalisation for asthma. Thorax. 2002 Oct;57(10):880-4. doi: 10.1 136/thorax.57.10.880. PMID: I2324675; PMCID: PMCI 746208.

18. Pauwels RA, Pedersen S, Busse WW, Tan WC, Chen YZ, Ohlsson SV, Ullman A, Lamm CJ, O'Byrne PM; START Investigators Group. Early intervention with budesonide in mild persistent asthma: a randomised, double-blind trial. Lancet. $2003 \mathrm{Mar}$ 29;36I(9363): I07I-6. doi: I0.10I6/S0I40-6736(03)I289|-7. PMID: 12672309.

19. O'Byrne PM, FitzGerald JM, Bateman ED, Barnes PJ, Zhong N, Keen C, Jorup C, Lamarca R, Ivanov S, Reddel HK. Inhaled Combined Budesonide-Formoterol as Needed in Mild Asthma. N Engl J Med. 2018 May 17;378(20):I865-1876. doi: 10.1056/NEJMoal7I5274. PMID: 29768I49.

20. Bateman ED, Reddel HK, O'Byrne PM, Barnes PJ, Zhong N, Keen C, Jorup C, Lamarca R, Siwek-Posluszna A, FitzGerald JM. AsNeeded Budesonide-Formoterol versus Maintenance Budesonide in Mild Asthma. N Engl J Med. 2018 May 17;378(20):1877-|887. doi: I0.1056/NEJMoa I7I5275. PMID: 29768I47.

2I. Beasley R, Holliday M, Reddel HK, Braithwaite I, Ebmeier S, Hancox RJ, Harrison T, Houghton C, Oldfield K, Papi A, Pavord ID, Williams M, Weatherall M; Novel START Study Team. Controlled Trial of Budesonide-Formoterol as Needed for Mild Asthma. N Engl J Med. 2019 May 23;380(21):2020-2030. doi: 10.1056/ NEJMoa I901963. Epub 2019 May 19. PMID: 3। I I 2386.

22. Hardy J, Baggott C, Fingleton J, Reddel HK, Hancox RJ, Harwood M, Corin A, Sparks J, Hall D, Sabbagh D, Mane S, Vohlidkova A, Martindale J, Williams M, Shirtcliffe P, Holliday M, Weatherall M, Beasley R; PRACTICAL study team. Budesonide-formoterol reliever therapy versus maintenance budesonide plus terbutaline reliever therapy in adults with mild to moderate asthma (PRACTICAL): a 52-week, open-label, multicentre, superiority, randomised controlled trial. Lancet. 2019 Sep I4;394(10202):919928. doi: 10.1016/S0I40-6736(19)31948-8. Epub 2019 Aug 23. Erratum in:Lancet. 2020 May 2;395(I0234): I 422. PMID: 3 I45 I 207.

23. Singapore Agency for Care Effectiveness (ACE). ACE Clinical Guidance for Asthma [Internet]. SG: ACE [Updated 2020 Oct I5; cited 202I June 28]. Available from: https://www.ace-hta. gov.sg/healthcare-professionals/ace-clinical-guidances-(acgs)/ details/asthma-optimising-long-term-management-with-inhaledcorticosteroid

\section{LEARNING POINTS}

- Recent guidelines recommend preventer (or controller) medications, particularly inhaled corticosteroid (ICS) as the mainstay of long-term asthma management to reduce poorly controlled outcomes and exacerbations of asthma.

- The Global Initiative for Asthma (GINA) and ACE Clinical Guidance (ACG) guidelines no longer recommends the treatment of asthma in adults and adolescents with SABA monotherapy due to safety concerns.

- Budesonide-formoterol has been approved in Singapore for the treatment of mild asthma to achieve overall asthma control, including the prevention and relief of symptoms as well as the reduction of the risk of exacerbations 